\title{
Far from rare: revisiting the relevance of idiopathic basal ganglia calcifications
}

\author{
João Ricardo Mendes Oliveira $\cdot$ Samy Scherb Steinberg
}

Received: 20 July 2010/ Accepted: 22 July 2010/Published online: 13 August 2010

(C) Springer-Verlag 2010

In their article Drs. Ashtari and Fatehi present an interesting report of a family with idiopathic basal ganglia calcification across different generations, highlighting the clinical heterogeneity amongst the affected [1].

Brain calcifications are visualised more often than ever before, and they show up in 1-2\% of patients who undergo computerised tomography (CT) [2]. A number of systemic and neurological disorders can lead to a diffuse pattern of brain calcifications and "Fahr type" calcification (striatopallidodentate calcifications), which are often found in idiopathic cases associated with normal biochemical and endocrinology screening.

Once considered, an extremely rare condition, idiopathic basal ganglia calcification, also known as "Fahr's Disease" (FD), has been reported more and more often. Probably, because neuroimaging techniques are getting cheaper and more available, increasing the number of patients scanned and diagnosed.

However, the nosology of this heterogeneous neuropsychiatric condition is unclear and still struggles for a standard diagnostic criteria. An ongoing debate suggests that this eponym, "Fahr's Disease", should be abolished, or used only for idiopathic cases, particularly because brain calcification is often found by neuroimaging in a wide variety of medical conditions [3].

Another intriguing consequence of the ramping use of neuroimaging techniques is the serendipitous finding of brain calcification during the investigation of milder symptoms, some of them with transient symptomatology, in emergency rooms or in asymptomatic subjects with massive calcifications and positive family history [4-6].

The understanding of the molecular basis of such phenotype, based in family members, might also contribute to a better understanding of other neuropsychiatric conditions with similar symptoms that might mimic "Fahr's Disease", such as Parkinson's Disease, Dementia, Schizophrenia and Mood Disorders.

\section{References}

1. Ashtari F, Fatehi F (2010) Fahr's disease: variable presentations in a family. Neurol Sci. doi:10.1007/s10072-010-0380-8

2. Fujita D, Terada S, Ishizu H, Yokota O, Nakashima H, Ishihara T, Kuroda S (2003) Immunohistochemical examination on intracranial calcification in neurodegenerative diseases. Acta Neuropathol 105(3):259-264

3. Oliveira JR, Oliveira MF, Lemos RR, Oliveira ML (2009) The current status of "Fahr's disease" nosology. Pract Neurol 9(5):302

4. Yoshikawa H, Abe T (2003) Transient parkinsonism in bilateral striopallidodentate calcinosis. Pediatr Neurol 29(1):75-77

5. Oliveira JR, Lima Filho JL, Zatz M (2009) Identical twins with idiopathic basal ganglia calcification ("Fahr's Disease") presenting with a remarkably similar pattern of neuroimaging findings. Parkinsonism Relat Disord 15(5):396-397

6. Sentimentale A, Matteoli M, Giovannelli M, De Dominicis C, Corsino M, Ferri E, Di Somma S (2010) Fahr's disease detected on a head CT scan in patient with "epileptic syncope" in the Emergency Department. Intern Emerg Med 5(3):263-265 